\title{
QOL in BPH patients after different methods of treatment
}

Jurij Čeredničenko, Šeškinès outpatient clinic Vilnius, Vytautas Kamarauskas, M. Marcinkevičiaus hospital Vilnius

\section{AIMOF STUDY}

This prospective study was to evaluate voiding,

sexual function, and their impact on patients whith BPH after ST and MT methods of treatment.
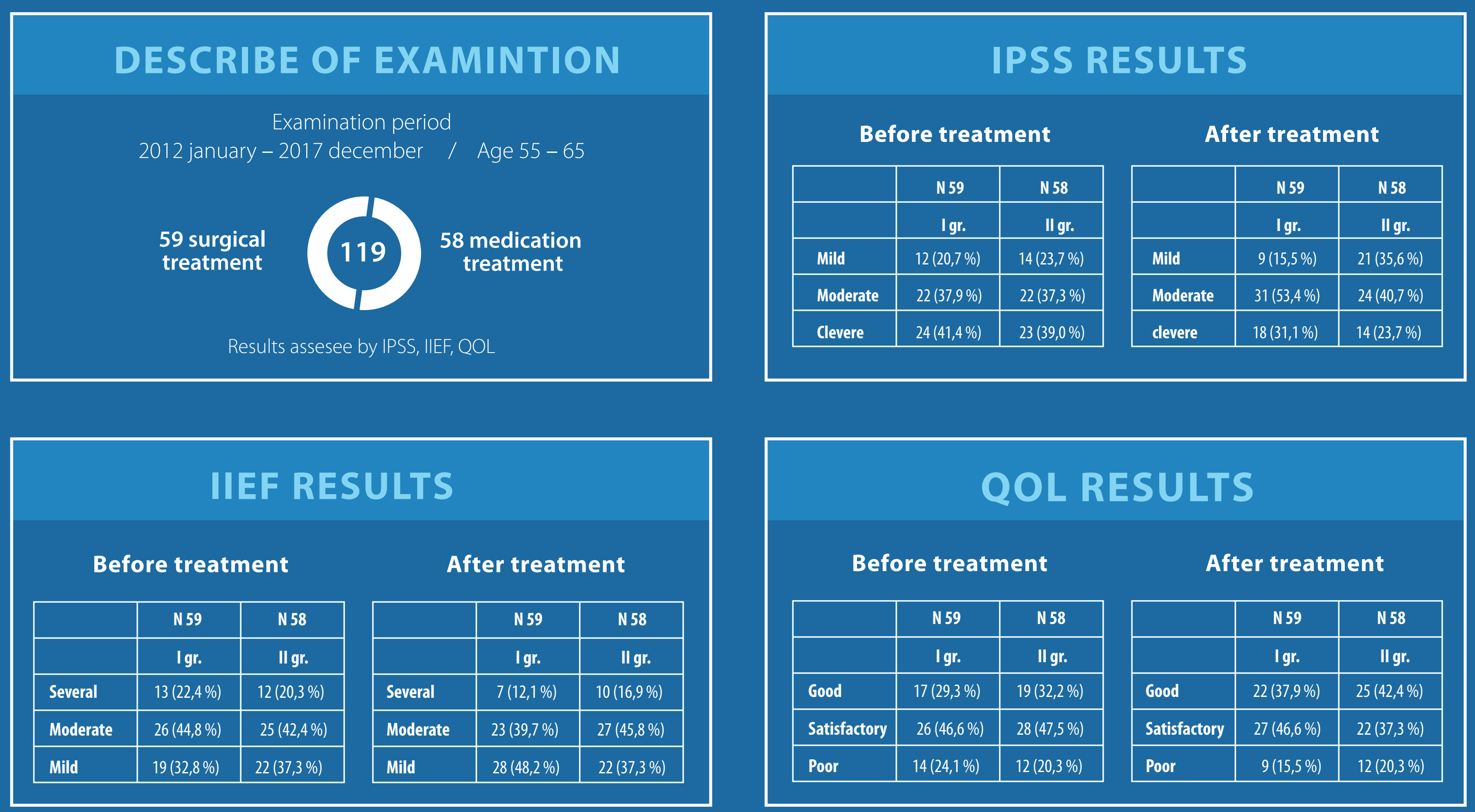

\begin{tabular}{|c|c|c|c|c|c|}
\hline \multicolumn{6}{|c|}{ QOL RESULTS } \\
\hline \multicolumn{3}{|c|}{ Before treatment } & \multicolumn{3}{|c|}{ After treatment } \\
\hline & N59 & N 58 & & N59 & N58 \\
\hline & Igr. & II gr. & & Igr. & II gr. \\
\hline Good & $17(29,3 \%)$ & $19(32,2 \%)$ & Good & $22(37,9 \%)$ & $25(42,4 \%)$ \\
\hline Satisfactory & $26(46,6 \%)$ & $28(47,5 \%)$ & Satisfactory & $27(46,6 \%)$ & $22(37,3 \%)$ \\
\hline Poor & $14(24,1 \%)$ & $12(20,3 \%)$ & Poor & $9(15,5 \%)$ & $12(20,3 \%)$ \\
\hline
\end{tabular}

